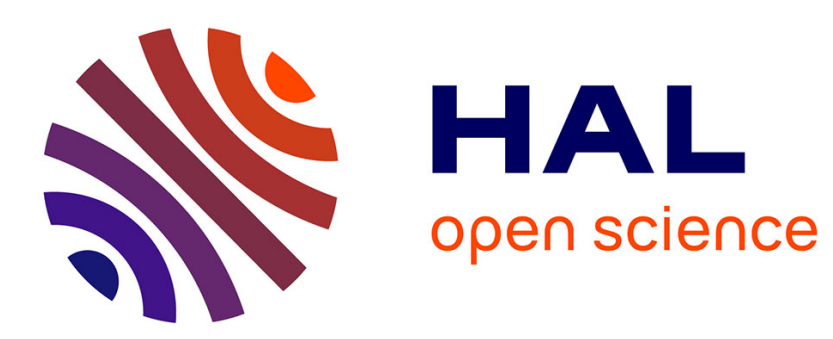

\title{
Project: the Just Necessary Structure to Reach your Goals
}

\author{
Julie Stal-Le Cardinal, F. Marle
}

\section{To cite this version:}

Julie Stal-Le Cardinal, F. Marle. Project: the Just Necessary Structure to Reach your Goals. International Journal of Project Management, 2006. hal-01204837

\section{HAL Id: hal-01204837 \\ https://hal.science/hal-01204837}

Submitted on 24 Sep 2015

HAL is a multi-disciplinary open access archive for the deposit and dissemination of scientific research documents, whether they are published or not. The documents may come from teaching and research institutions in France or abroad, or from public or private research centers.
L'archive ouverte pluridisciplinaire HAL, est destinée au dépôt et à la diffusion de documents scientifiques de niveau recherche, publiés ou non, émanant des établissements d'enseignement et de recherche français ou étrangers, des laboratoires publics ou privés. 


\section{Project: the Just Necessary Structure to Reach your Goals.}

Julie Stal-Le Cardinal, Franck Marle ${ }^{1}$

Ecole Centrale Paris, Chatenay-Malabry, France

\section{Ecole Centrale Paris}

Industrial Engineering Department / Laboratoire Génie Industriel

Grande voie des Vignes

92295 Châtenay-Malabry

France

franck.marle@ecp.fr

Tel: (33)613061415, (33)141131568

Fax: (33)141131272

\footnotetext{
${ }^{1}$ Corresponding author. Tel: 33-1-41131568. e-mail address: franck.marle@ecp.fr
} 


\title{
Project: the Just Necessary Structure to Reach your Goals.
}

\begin{abstract}
This paper proposes a definition process of the project structure which should be constructed in order to reach the objectives and to deliver the final results.

The first part of the paper specifically describes this process, with its inputs, tools and methods and outputs. The inputs of this process, initial situation, objectives and environment, are described in part 2, with research proposals on environment management. Other research proposals about tools and methods are presented in part 3, focused on the topics of scope and activity definition and resource assignment. Concrete propositions stemming from research works and from their application at VALLOUREC and PSA PEUGEOT CITROEN will be presented all along the paper.
\end{abstract}

Keywords: managing projects, processes, design, competence assignment, dysfunctions 


\section{Introduction}

A project is a temporary endeavor undertaken to reach some objectives and to deliver some results. The project is then a change vector in companies, markets and society. It consists of a start, an initial situation, and of a finish, with results that change the company's situation, in terms of internal performance, product offer, communication tools, and so on.

Project management consists of the whole concepts, methods and tools, in order to bring the project from start to finish, which means in order to reach the objectives and to deliver the results of the project.

The project lifecycle can be described in several ways, for instance with the PMI ${ }^{\circledR}$ processes: initiating, planning, executing and controlling, closing. The planning process consists of identifying, estimating and preparing the whole activities that have to be executed in order to reach the objectives and to deliver the results. Its output is the project plan, which means the project structure, deliverables, activities and resources, estimated on time, cost and quality dimensions.

According to a survey executed by the Standish Group International in 2000 [26], 80\% of project successes or failures may be linked to planning, like bad scope definition, bad stakeholder analysis, bad activity decomposition and bad resource assignment.

The planning process is then very important and not under control. Very important, because the decisions made upstream in planning phase have much bigger consequences in the downstream execution phase: failing to plan is planning to fail. Not under control because it is impossible to predict the future, we can just make forecasts and estimations. But as the available information is not sure, and as the context is very complex, uncertain and changing, the plan is always not reliable. 
The scope of the paper is about the process from the idea, the objectives to the project structure (planning), and not from the structure to the results (the execution). We call it the project structure definition process.

\section{Project Structure Definition}

A project is a transformation process, from an initial to an expected final situation, evolving in an often complex and changing environment.

The initial situation is composed of:

- The company's corporate strategy,

- Historic and standards: global or specific to the company,

- Initial resources available in the company: human resources, skills, knowledge, material resources, money,

- Constraints and assumptions

The description of the final situation gives the project objectives. Project objectives may result from or be consistent with the corporate strategy, and may be a response to a constraint (legal, social, ecological) or an opportunity / risk (technological or financial for instance). They can be expressed with customer requirements analysis like functional analysis for product development. Therefore, to develop a new product, for instance, the beginning of the project consists in defining the expected functions, the expected delivery time and the budget. In figure 1, the process is displayed with a loop, in order to show the existence of the project objectives at the beginning, and their comparison with project results after execution.

The project environment is composed with the whole stakeholders involved in the project lifecycle. 
The transformation from initial to final situation can be made by planning and executing some project activities, using project resources and organizing in a logical way. It may include product-oriented activities, human management activities, and quality or procurement activities. This transformation is what is called project structure in this paper. It is possible to use tools and methods to make this structure definition. Examples of tools and methods are Work Breakdown Structure, Gantt charts, resource assignment matrix and project baselines (performance, cost).

The focus of the paper is about project structure definition. The figure 1 gives illustration of the project structure definition process, and its location in the global project lifecycle. The focus of the paper is only to study the local structure definition process. It may be implemented in any of the existing standards about project management and project lifecycle, like PMI®, IPMA, six-sigma for example.

The initial situation, objectives and environment are described as the inputs of the project structure definition process, in part 2 "Inputs of the process", with a research focus on environment management. The research proposals about tools and methods are in part 3 "Tools and methods", focused on the topics of scope and activity definition, and resource assignment.

Everything is uncertain and may change during the project lifecycle: objectives, environment, resources, constraints and assumptions, and so should the structure change. It is not in the scope of this paper to see when and on which conditions the structure must change.

\section{Inputs of the process}

We consider here any project that takes place in an industrial environment. The definition of the project structure has to take into account parameters presented in the three following parts: 
the initial situation, the objectives and the environment. In each part, we are going to describe each of these parameters, and analyze their dysfunctions and their consequences. For the last one, the project environment, a proposal is made from a research work to help to manage environment during the project.

\section{Initial situation: to know where we are today}

\section{$\underline{\text { Description }}$}

Information, here, depends on the situation of the company, and depends on the initial need of the project. The project should be aligned with the corporate strategy, so the project manager must be able to show how his project contributes to the global strategy achievement of the performing organization. The project manager should take into account additional information, like historic and standards, initial available resources, constraints and assumptions.

\section{Dysfunctions and consequences}

The initial need is seldom clearly formulated. It is the responsibility of the project manager, or the management or sponsor, if the project manager is not yet assigned, to clarify and refine this need in order to describe the project stakes, the justification of the project, and elaborate the first detailed specifications.

As the project manager is part of the description of the initial situation, an assignment dysfunction may involve dysfunctions for the project. For example, a project manager assigned too late or unofficially, or assigned to a project he does not have the skills for, may involves delays, under-quality and non satisfaction of the project objectives and of the customer.

Moreover, if the company does not have any high level indicator to know (in terms of performance, competencies, procedures and quality) where it is, it will be difficult then to 
know if means are well-planned with regard to the objectives, to the initial situation and to the environment.

\section{$\underline{\text { Proposals }}$}

There is no proposal to better control the definition of any initial situation in this paper. The assumption is that the company has made the decision to launch a project, taking into account its own situation and the need. The company is then ready to give resources and expects results of the project.

\section{Objectives: to know where we want to go}

\section{$\underline{\text { Description }}$}

Objectives are defined here as the expected end of the project, the goals that need to be reached. To define objectives involves delimiting the scope of the project, including its frontiers. What is not in the scope is not in the project, and reciprocally.

Objectives may be clearly defined with a project requirements definition, or a project specification. It is a formal document where may be detailed: the context and stakes of the project, the goals, the major deliverables, the customer(s), the frontiers, the global cost and deadline and the organization type (project manager, matrix or functional or project team, sponsor, ...). It may be more or less detailed, and it may include functional or technical specifications. The most important thing is that it should correspond to the customer needs and expectations.

\section{Dysfunctions and consequences}

Dysfunctions and consequences are relative to the definition of perimeter, the existence of specifications of the project and the determination of available resources. Approaching the limits of the project, knowing what we do and what we do not do in the project is often an important moment of negotiation. It allows to enrich or to decrease the expected objectives. 
The earlier on a project we approach this clarification of the objectives, the less danger we have of skidding and not achieving them [9].

A dysfunction can be characterized by a difference between the expected action and the realized action and thus a non-achievement of the objectives [25]. The objectives can be not SMART (Specific, Measurable, Achievable, Realistic, Time-related), as proposed by Drucker [7], which reveals a dysfunction.

According to the Standish Group survey [26], the influence of objectives definition is important on project success or failure. People have declared this as a cause for $21 \%$ of the successes and $32 \%$ of the failures, decomposed into complete (or not), realistic (or not) and stable (or not) specifications.

The main dysfunction here is a difference between the project specifications and the customer needs and expectations, for instance if one forgets one need, or puts a specification not needed by the customer.

\section{$\underline{\text { Proposals }}$}

The list of dysfunctions and their consequences is in itself one proposal, but no other solution is introduced. Proposals about objectives definition and control are not in the scope of the paper.

\section{Environment: to know what is around us}

According to a Standish Group survey [26], the influence of environment is important on project success or failure. People have declared environment as a cause for $30 \%$ of the success and $28 \%$ of the failures. This part details some facts about complexity of interactions inside a project and outside the project, with its environment. Some proposals are made about interactions description, using a project interactions model [14]. 


\section{$\underline{\text { Description }}$}

In a project, there are a lot of exchange flows, of information, decisions and material or financial items, which make the project complex, as described by Baccarini [4] or Williams [31]. For example, with $\mathrm{N}$ persons, there are $\mathrm{N}^{*}(\mathrm{~N}-1) / 2$ possibilities of communication flows. These persons, or organizational structures, have different interests and different influence capacities, positive or negative, and these interests and influences may change during the project. The influence between two persons may be in only one way, or reciprocal. The action of identifying the environment of a project, in order to anticipate what influences, positive or negative, may affect the project or may be affected by the project, is called stakeholder management.

\section{Dysfunctions and consequences}

If only one stakeholder is not taken into account, forgotten or neglected, the risks of the project are increased. A project can be initiated, modified or stopped by influence of only one stakeholder.

For some stakeholders, below is an example of possible dysfunction and its potential consequence:

- The customer/user: if not taken into account, the customer may not validate the project, or may not pay, or may not want to work with us any more.

- Executive management, project sponsors, program director, steering committee and executive committee: they have the power to modify or to stop the project, and they may do it if they do not have proper and periodic reporting about the project and its stakes.

- Other projects: a project shares priorities and resources with other projects. Not to be aware of the other projects, and not anticipating our own resource needs in regard to other projects needs may conduct to a global constraint impossible to solve. 
- Other items, like departments, suppliers, sub contractors, partners, ...

\section{$\underline{\text { Proposals }}$}

The project interactions model

The most known tool is the stakeholder analysis. We have elaborated, in collaboration with PSA Peugeot Citroën, a model describing the interactions existing inside a project, and between the project and its environment. This model is detailed in [14], and is standard wherever we are in the project hierarchy. It has been built in order to complete stakeholder analysis, and to be applicable at each level, sub-project or work package, and not only at the project level. It is composed of seven types of interactions, and of some objects, like project, objective, deliverable, activity, process and actor:

- The hierarchical link: exists in WBS and PBS for example.

- The sequential link: exists in every project schedule, and shows time dependency.

- The contribution link: a result of object O1 (a project) may contribute to the result of object O2 (an objective, or another project).

- The influence link: $\mathrm{O} 1$ (sponsor) may modify $\mathrm{O} 2$ (project), or the result of $\mathrm{O} 1$ (project) may impact $\mathrm{O} 2$ (users).

- The resource link: two objects share the same critical resource.

- The proximity link: O1 looks like O2, which may give an opportunity to reuse experience and best practices.

- The exchange link: is only an exchange of information and data.

\section{The integration of external constraints}

In concurrent engineering, the goal is to integrate downstream constraints in the upstream activities, in order to avoid rework and waste. The goal is exactly the same in identifying the six other types of interactions: we shall integrate the whole constraints of the environment 
before to endure them, because the consequence of a mistake in planning is multiplied by ten or hundred in execution.

A last key point of this part is that environment influences the project structure. If one stakeholder is forgotten, the structure will be different. If the importance given to one stakeholder is different, the structure will be different. The proposal is then to integrate environment during the project structure definition process, in order to perform right stakeholder management during the rest of the project. Our model helps to identify, characterize and visualize interactions, as detailed in [14], and a software prototype was performed and tested in PSA Peugeot Citroën, on some projects of their progress plan. It was a 250-projects plan consisting of the whole actions of internal improvement, transformation, what we can call support. The test showed the complexity of this project network, and demonstrated the difficulty to manage this properly. It had an impact on project structure definition, but also on multi-project management. Now, there are much fewer and much bigger internal projects in this company to limit complexity in the management of such a project network.

\section{Tools and Methods}

We have first defined the project structure concept, then the inputs of the process that leads to this structure. We are now going to propose tools and methods to help building the structure of a project. The definition process of any project structure is a decision process made of two main sub-processes: the decomposition of the project and the resource assignment. In this chapter, each sub-process is described, then examples of dysfunctions are analyzed and our propositions of improvement are presented and justified. A last point not developed in this paper is about risk management, which consists of identifying, assessing and responding to the whole potential events, positive or negative, that may affect the project, because the project structure will be modified, enriched and refined. 


\section{Decomposition process}

\section{$\underline{\text { Description }}$}

Decomposition is a cognitive and complex problem-solving process. A non-human tool can not make decomposition, except by repeating previous projects or by using standard templates. It is the operation of expressing an object into several smaller ones. Some examples of decomposition are the Work Breakdown Structure or Product Breakdown Structure. The major deliverables of the project or the main components of the product are decomposed into smaller, more manageable items. It allows better managing and controlling of each lowest-level element, called work package for WBS. It allows assigning each work package to one organizational and financial unit.

The input is often called «father » and the outputs «sons ». The outputs are not unique; it may be several decomposition possibilities. So, decomposition is also a decision-making process, a choice between decomposition alternatives.

\section{Dysfunctions and consequences}

- Frontiers definition problems between two sub-objects: authority balance, responsibility sharing, time waste due to bad scope limits, rework or work made two times ...

- Project decomposition may be not consistent with the existing organization decomposition: waste of time due to organizational and personal conflicts,

- The execution of the whole sub-objects may not give the object: under-quality, delays, scope variance, non satisfaction of objectives and customer,

- The reticence to use formalized and rigorous methods for a day-to-day action: but decomposing a project is far more complex than decomposing the tasks for planning a holiday trip. 
Consequences of a bad decomposition on project performance are big, because the rest of the planning process is based on it, like cost, resource and time estimating, quality, communications and procurement activities. So, it involves cautiousness and use of risk mitigation actions, like the methods proposed below.

\section{Proposals}

Proposals are on potential decomposition generation and evaluation. The project manager's role is then to apply the decomposition decision, by communicating to concerned people, and finally to keep experience and lessons learned for next projects and next decompositions.

\section{Generation step}

Based on other approaches, like [20], [27] and [32], we have defined a four-step solution generation process for project decomposition, consisting of:

- The identification of specific parameters of the object that describe its context. It allows to know what can be reused from past for this project, and what will be reusable from this project to future projects,

- The information research into historic and standards,

- The decomposition itself of the object, whether by using one or more decomposition criterion, described below, or by using creativity methods,

- The identification of additional interactions with other objects, which are directly involved by the decomposition process, like described below.

\section{Decomposition criteria}

The proposal for decomposition criterions is expressed into a list of eight elements:

- by phase,

- by profession,

- by department,

- by technical domain, 
- by objective or function,

- by mechanical or structural sub-system,

- by geographical location,

- by addressee, in terms of population or process.

Other criteria lists are available [10].

There are two types of decomposition: mono- and multi-criteria. Every project decomposition is mono or multi-criteria, with the criteria of the list described above.

For example, a new bicycle development project may be decomposed like this: project management, handlebar, fork, transmission, wheels, safety equipment, mechanics, prototyping, manufacturing, distribution, marketing/sales.

This decomposition is a mix of organic (handlebar, fork, transmission, and wheels), technical (project management, safety, mechanics) and sequential decomposition (prototyping, manufacturing, distribution, marketing/sales). It involves more risk, on the frontiers definition. The other possibility would be to decompose first by organs, then by technical domain, and finally by phase, but the project structure would have three levels instead of only one, which is heavier. The best decomposition is the best compromise between scope, time and organizational parameters, which means the less risky.

\section{Additional interactions}

Decomposition involves other interactions than the only hierarchical link between father and sons. These other links are between the sons or between one son and another object elsewhere in the project. But there is no reciprocity: if there is a link between two objects, it does not imply that it is an additional link created by decomposition.

Mono-criteria and homogenous decomposition creates between the sons a link corresponding to these criteria: for instance, decomposing a project among its phases involves a sequential link between some of these phases. Criteria "by phase" => additional "sequential" link. 
A multi-criteria decomposition creates multiples links corresponding to each criterion. A multi-criteria heterogeneous decomposition creates automatically between the sons several types of links, corresponding to each criterion. The decomposition of a project into electronics, mechanics, data processing and project management creates contribution links (from project management to the other technical areas), sequential links (from electronics to data processing) and exchange links (between mechanics and electronics).

These links should not be forgotten, as they are created in an invisible and indirect way.

\section{Evaluation step}

Every decomposition choice should be done only from an «a priori » evaluation, before the project is executed:

- Relative evaluation by comparing several alternatives,

- Absolute evaluation if only one decomposition is proposed.

The aim of this evaluation is to assess if the decomposed structure has a chance or not to reach the project objectives. In order to realize this assessment, a list of questions has been developed, split in 7 main questions. The complete list is detailed in [14]:

- Is the decomposition complete?

- Is the decomposition homogeneous?

- Does the number of sons lie between three and seven?

- Is the decomposition innovating or was it already tested in preceding projects?

- Is the decomposition consistent among the complete project?

- What are the additional links generated with the hierarchical link?

- What is the flexibility of the decomposition? Its robustness?

The problem with standard decomposition is that it does not take into account additional interactions, it is not evaluated, and it does not allow the team members to be creative in the construction of their own decomposition. It should be used only as a basis for inspiring 
decomposition, not as a rigid tool [18]. Standardization should not be at the scale of the company but more at a project scale. Payne [21] proposes, for instance, the planning and control of programs of projects of different type.

\section{Synthesis: tips for a right decomposition}

This is developed in [13] and [14], and was implemented in a simplified manner in PSA Peugeot Citroën as a procedure included in project planning:

- Try to do homogeneous decompositions,

- Always evaluate the chance of the decomposed structure to succeed. By comparison if there are several alternatives, but it is not necessary,

- Identify the additional links generated by the decomposition,

- Take into account the parameters which may influence the decomposition result of the decomposition process, like the context of the project, the pressure on the project manager, the liberty and autonomy, the innovation degree, and the existing standards.

\section{Assignment process}

Our work and proposals about the assignment process is based upon a study we have made within the Vallourec Group. During this collaboration, we have worked with two units and more than 20 projects during 2 years. The purpose was to help in project management and more specifically to help in the choice of people as project manager or member of a project team. This is a key stake, and Turner [28] describes a "project as a temporary organization, (...) as an agency for assigning resources to the management of change within the functional organization".

\section{$\underline{\text { Description }}$}

In a company, projects are the translation of the strategic axes into actions. At the strategic level of a company, decision-makers have to choose people/actor to be project managers and 
then, a project manager has to build up his project team, he can choose actors from the company or external people. An example is the choice of contractors during the procurement phase [22]. We define an actor as a human being among company means. Material resources, software, hardware, people are part of the means in a company. What distinguishes an actor from the other means is that an actor has competencies quantified by a level, can make decisions and is able to characterize the impact of his action in advance.

So as to take part in a project, people/actors have to be chosen as responsible for some actions. The success of the project depends among others on the choice of the actors in the project [5]. The "choice of actor" is a decision made by a decision-maker that consists in selecting, evaluating and choosing a person to accomplish an action. Mezher [16] considers the decision as "a process which generates and evaluates alternatives and which makes choices among them."

\section{Dysfunctions \& consequences}

The Standish Group survey already introduced before gives some statistics about the importance of human resources in projects: sufficient and competent resources represent more than $10 \%$ of successes and failures of the studied projects [26]. We propose here an analogy with the maintenance area [3] where "a failure is the stochastic cessation of an entity aptitude to accomplish a required function." According to Villemeur [29], "after a failure identification, the entity is considered out of order. A breakdown is always due to a failure." By analogy, we consider an actor in a company as an entity whose function is to decide. Reginato and Ibbs [23] consider a project actor as someone who can make decisions including the whole parameters of the project, managerial and technical. If the decision-maker is not able to make his decision, then there is a dysfunction, because he is not able to realize his function. 
We, therefore, propose the following definition of a dysfunction in a decision process: a dysfunction is a stochastic cessation of an actor's aptitude to make a decision. If the action expected to be accomplished has not been realized, then there is a dysfunction. The gap between the effective result and the negotiated objective to be reached is called the dysfunction value.

Dysfunctions are decomposed in elementary dysfunctions and represented along the DTL (Decision Time Line, [25]). Each elementary dysfunction is related to a DTL step, independent from each others and cannot be studied as a combination of dysfunctions. The gap due to a dysfunction is then evaluated. Using our model, it is possible to give a temporal characterization of dysfunctions as well as a functional characterization that allows classification of various dysfunction types. Concerning actors' choice, we make the hypothesis that the reasons of the dysfunctions result from problems of competence. Competences concern the decision-maker or the chosen actor. We suggest classifying these types of dysfunctions on a model of competence. Other models exist, like [6], [8] and [19], or selection criteria definition, like [17]:

- Knowledge: know-who, know-why, know-what,

- Know-how: technology, techniques, knacks,

- Attitude: behavior, will, identity.

\section{$\underline{\text { Proposals }}$}

\section{The target process}

The target process is a process to follow for a specific type of decision, choice of actor, and which helps to avoid dysfunctions, as illustrated in figure 2 . But even if the different steps are properly followed, risks of dysfunctions still exist, nothing can completely erase them. 


\section{How to avoid dysfunctions? The decision card}

The previous target process becomes a reality in an index card performed by the project managers which serves for discovering the risks a priori (context and quantification of tasks to perform), for estimating the decisions a posteriori (steps 2 to 6 of the target process) and for preserving the information with the aim of statistics, for example (result analysis, recommendations and capitalization).

Once such a card is completed, project managers, in the Vallourec Group, are able to analyze the reasons of the dysfunctions. With a consequent number of cards, it is possible then to study the general trend for a given company to cope with dysfunctions.

The capitalization database provides a means for dysfunction prediction, by capturing the firm's experience from prior decision-making tasks. Software accessing the capitalization database and the decision-making model can give an early warning to a decision-maker when an action or decision-making strategy is likely to lead to a known dysfunction and consequently a problem in quality, cost, or delay.

The capitalization database can also be used to conduct a statistical study of dysfunctions within the firm: what are the risky steps in the decision-making process, what are the main sources of dysfunctions, what are the main effects...

As far as Vallourec is concerned, statistics have been made to detect the risky steps in the decision-making process concerning a particular type of project. The risky steps are indeed different from a product development project to a human resources project, for instance.

\section{Conclusion}

The aim of this paper is to help in the definition of a project structure that will correspond to the expected deliverables for a given project. 
The main message is that building a correct project structure is achievable and gives more guarantee for success. On contrary, a bad structure is a guarantee for failure: failing to plan is planning to fail. We, then, show the feasibility of formalizing and managing the project structure definition process, by using innovating concepts and tools, in the area of interactions management, decomposition process and resource assignment process.

This work is relevant for two reasons:

- Some recent statistics show the importance of projects and project management in companies and societies, and the importance of the planning phase on the rest of the project.

- The implication of two big companies as VALLOUREC and PSA PEUGEOT CITROEN in this research work, with their concern about the efficiency of their actions, shows that this topic is in their current preoccupations.

Practically, the concepts presented here have been transformed into industrial tools, like procedures and software modules. The reader could then gain advantage by using concrete templates, communication modules and decision-making tools.

The ideas of future developments are about

- Evaluation of the impact of the structure on the project success (evaluation "a priori”),

- Periodic re-estimation of the probability of success with the current structure (continuous evaluation),

- A procedure for correcting a structure with a low success probability and implementation of the corrections in an ongoing project (corrective actions). 


\section{References}

[1] Agonino A, Michelena N. Qualitative Decision Analysis. Qualitative Reasoning and Decision Technologies, 1993. p. 285-293.

[2] Argyris C. Personality and Organization. Harper, New York, 1957.

[3] Artikis T, Jerwood D, Moshakis J, Voudouri A. A Stochastic Model for Proactive Risk Management Decisions. Mathematical Computer Modelling. 1997. Vol. 26, N7. p. 87-95.

[4] Baccarini D. The Concept of Project Complexity - A review. International Journal of Project Management, Vol 14 Iss 4, August 1996.

[5] Belout A, Gauvreau C. Factors Influencing Project Success: the Impact of Human Resource Management. International Journal of Project Management, 2004.

[6] Crawford L. Profiling the Competent Project Manager. Proceedings of PMI Research Conference 2000, PMI.

[7] Drucker P. The Practice of Management. Harper Business, 1954.

[8] Gareis R. Competences in the Project-Oriented Organization. Proceedings of PMI Research Conference 2000, PMI.

[9] Goh S, Richards G. Benchmarking the Learning Capability of Organizations. European Management Journal. 1997. Vol.15, N5. p. 575-583.

[10] Hubka V. \& Eder W. Functions Revisited. $13^{\text {th }}$ International Conference on Engineering Design, August 2001.

[11] Jensen M, Meckling W. Theory of the Firm: Managerial Behavior, Agency Costs and Ownership Structures. Journal of Financial Economics. 1976. N³. p. 305-360.

[12] Johansen R, Martin A, Mittman R, Saffo P, Sibbet D, Benson S. Leading Business Teams - How Teams can use Technology and Group Process Tools to Enhance Performance. Addison Wesley Publishing Company, USA, 1991.

[13] Marle F. Plan more by Planning less: Contributions to a Recursive Planning Process, Proceedings of PMI Research Conference 2002, PMI.

[14] Marle F. Information Model and Methods in order to Help Decision-Making in Project Management, PhD thesis, Ecole Centrale Paris, 2002.

[15] Medcof J, Hauschildt J, Keim G. Realistic Criteria for Project Manager Selection and Development, Project Management Journal, PMI, September 2000. 
[16] Mezher T, Abdul-Malak MA, Maarouf B. Embedding Critics in Decision-Making Environments to Reduce Human Errors. Knowledge-Based Systems, n¹1, p.229-237. 1998.

[17] Midler C. L'auto qui n'existait pas, management des projets et transformation de l'entreprise. InterEditions. 1993.

[18] Mulenburg G. Report of Research Examining the Characteristics of Managers of Complex Contemporary Projects in the NASA, Proceedings of PMI Research Conference 2000, PMI.

[19] Nakatani M, Nishida S, Hosono Y, Yamaoka T. Coordinated Interfaces for Real-Time Decision Making in Hierarchical Structures. IEEE95. Vol. 2. p. 1568-1573.

[20] Pahl G, Beitz W. Engineering Design. Springer. 1996.

[21] Payne JH, Turner JR. Company-wide Project Management: the Planning and Control of Programmes of projects of different type, International Journal of Project Management, Vol. 17, No. 1, pp. 55-59, 1999.

[22] PMI Standards Committee. Project Management Body Of Knowledge. PMI. 2000

[23] Reginato J. IBBS W. Project Management as a Core Competency, Proceedings of PMI Research Conference 2002, PMI.

[24] Schweyer B. Formal Specifications for a Project Management Approach. IEEE95. Vol. 2. p.1170-1175.

[25] Stal-Le Cardinal J. A Study of Dysfunctions within Decision-Making Process. Particular Focus on the Choice of Actor. PhD thesis, Ecole Centrale Paris, 2000.

[26] Standish Group International. IT Project Survey. PM Network. September 2000.

[27] Thomson G. Requirements Engineering - Laying the Foundations for Successful Design, $13^{\text {th }}$ International Conference on Engineering Design, August 2001.

[28] Turner JR, Müller R. On the Nature of the Project as a Temporary Organization, International Journal of Project Management, Vol. 21, pp. 1-8, 2003.

[29] Villemeur A. Sûreté de fonctionnement des systèmes industriels, fiabilité, facteurs humains, informatisation. Paris 1988.

[30] Voeten B, Kroep L. Human Resource Allocation in a Multi-Project R\&D Environment, International Journal of Project Management. 1998.

[31] Williams T. The Need for New Paradigms for Complex Projects. International Journal of Project Management. 1999.

[32] Zeng Y. GU P. An Environmental Decomposition-based Approach to Design Concept Generation, $13^{\text {th }}$ International Conference on Engineering Design, August 2001. 
Figure 1. The location of project structure definition in the global project lifecycle

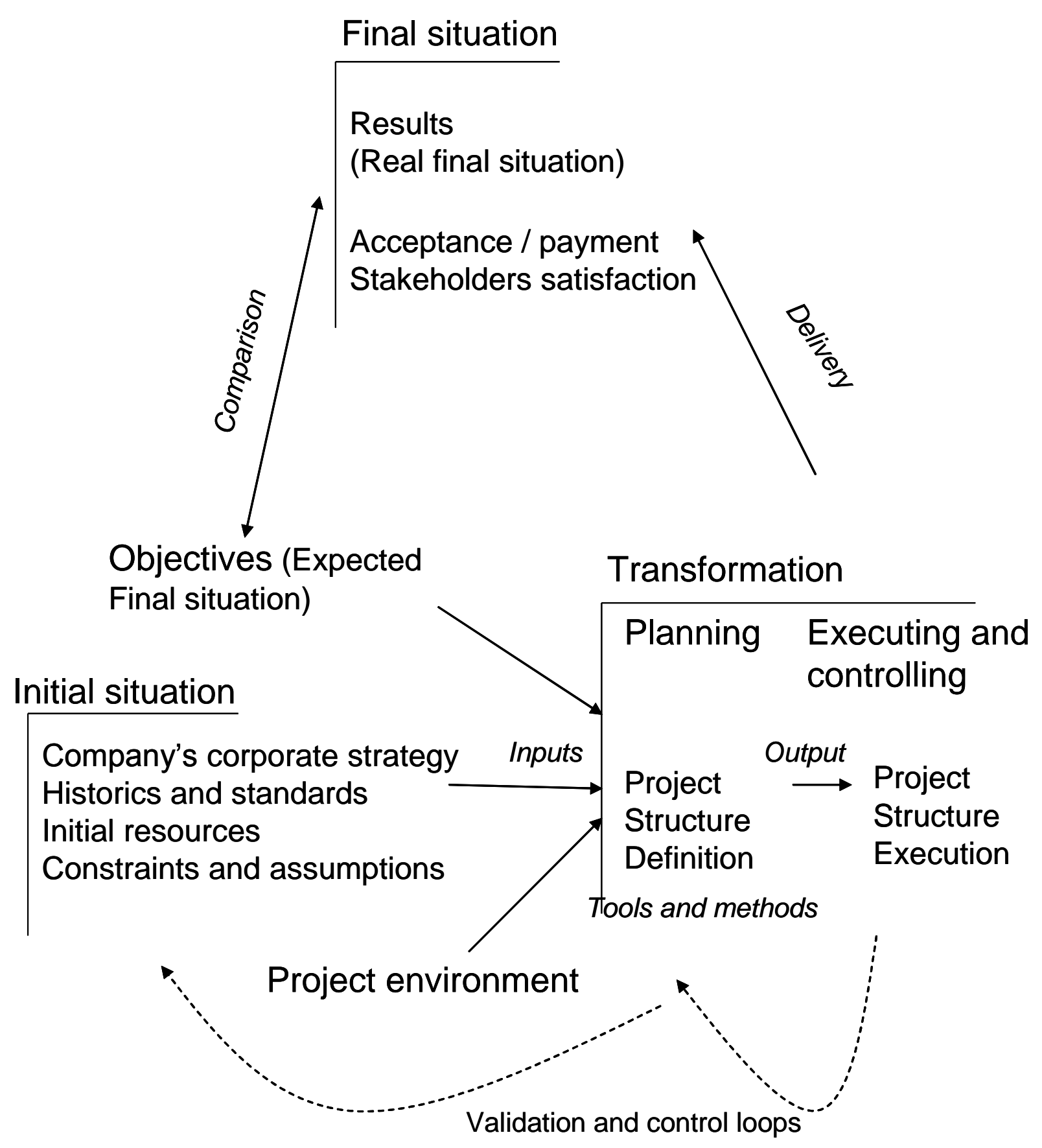


Figure 2. The target process as a core process for a decision-maker

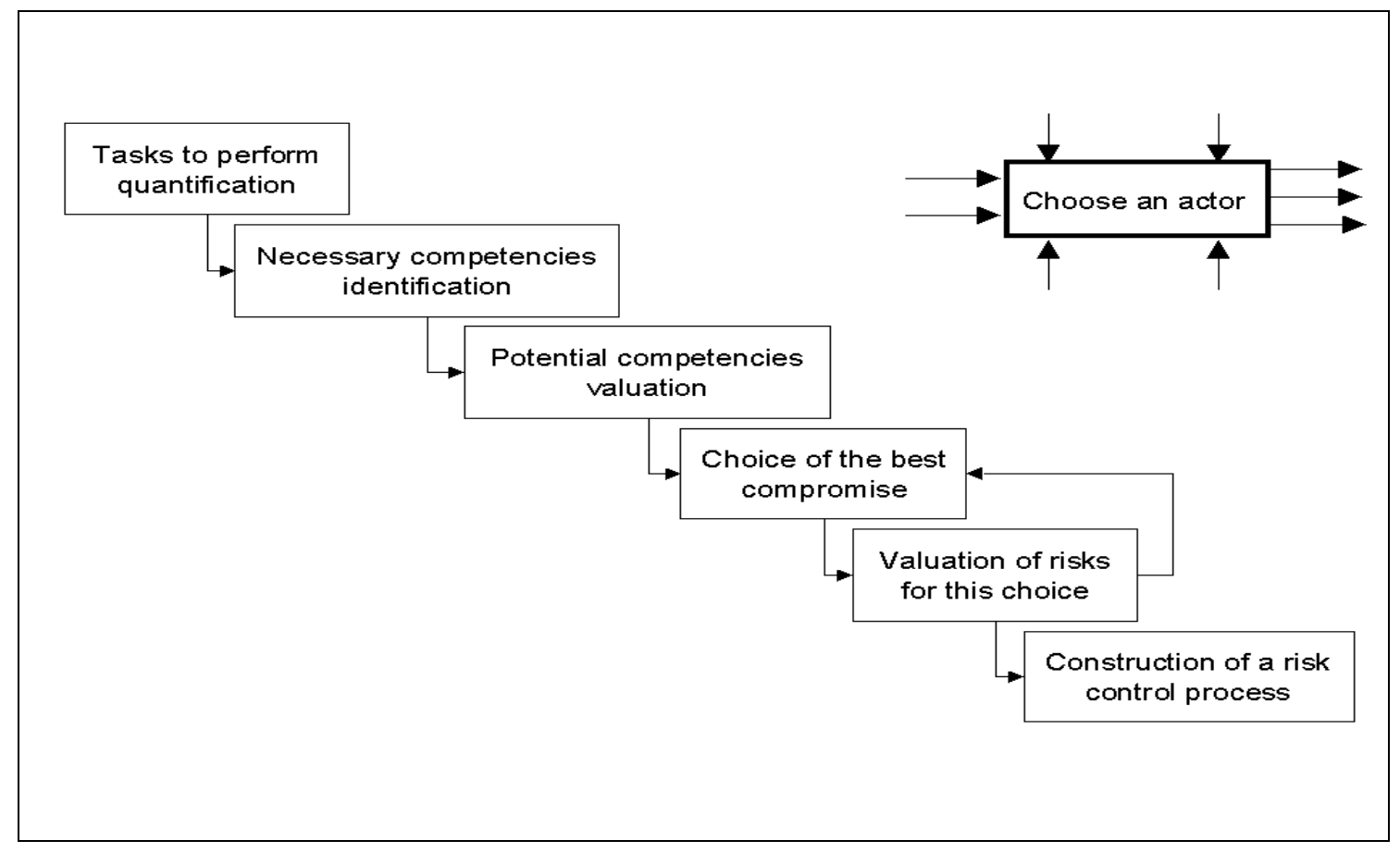

